\title{
The value of psychiatrists in leadership and management
}

\section{ARTICLE}

\author{
Jennifer Perry \& Fiona L. Mason
}

\begin{abstract}
SUMMARY
The health and social care landscape in the UK is changing, and there is now, more than ever, a real need for doctors to embrace leadership and management. Evidence shows that medical leadership is associated with better outcomes for patients. Psychiatrists are particularly well suited to such roles, given the interpersonal skills and self-awareness that they develop in their training. In this article, we examine the role of the psychiatrist in leading at a patient, team and organisational level and the impact this has. We also discuss different leadership and management styles.
\end{abstract}

\section{LEARNING OBJECTIVES}

- Understand why good medical leadership and management by psychiatrists is essential in healthcare in current times

- Learn how psychiatrists lead at a patient, team and organisational level and the impact this has

- Appreciate why psychiatrists can make good leaders, recognising the parallels between clinical practice and leadership

\section{DECLARATION OF INTEREST}

None

There are many definitions of leadership and management. Box 1 highlights some of the main differences between the two. It is apparent that, in the constantly changing and evolving system of public healthcare, the two are closely linked and equally necessary (Department of Health 2010).

The UK's health and social care landscape is changing; patients are living for longer with multiple long-term conditions. Healthcare is centrally state-funded and free at the point of delivery. Austerity puts pressure on healthcare systems as resources are squeezed; this makes it difficult for high-quality care to be delivered. It is in situations such as these that exceptional medical leadership is required. The most important opportunities to improve productivity and reduce cost are to be found in unwarranted variations in clinical practice (Ham 2013). Don Berwick has described how the failure of healthcare systems

\section{BOX 1 Differences between leadership and management}

- Leadership concerns developing vision and strategy. It focuses on people, on the future and on areas where there is often limited certainty and no agreement. Outstanding leaders also develop the leaders of the future.

- Management is about planning, organising, budgeting, troubleshooting and delivering results through the efforts of others; it focuses on efficiency and the present. Management operates best where there is certainty and agreement.

stems from a number of areas of waste, which are listed in Box 2 (Berwick 2015).

It is essential to drive prevention, early diagnosis and intervention, as well as to integrate responses to physical and mental healthcare. It is necessary to deliver effective coordination of care, engage patients, support self-management, monitor outcomes and offer good medicines management. Tackling variations cannot be done by politicians or managers. Instead, it requires every clinical team to take responsibility for reviewing its use of resources with the aim of improving the quality of care and reducing costs.

There are many healthcare organisations in which relationships between clinicians and managers are strained. Historically, managers have spent time chasing targets, which has led to the disengagement and disempowerment of staff. Although government targets have led to service

B0X 2 Areas of waste which contribute to the failure of healthcare systems

\section{- Overtreatment}

- Failures to coordinate care

- Failures in care delivery

- Excessive executive administration costs

- Fraud and abuse

(Berwick 2015)
Jen Perry is a general adult psychiatry trainee at South London and Maudsley NHS Foundation Trust. She wrote this article when she worked as a Clinical Fellow on the National Medical Director's fellowship scheme. During her fellowship, she was based at the Royal College of Psychiatrists and St Andrew's Healthcare, London. Fiona L. Mason is a Professor at the University of Buckinghamshire. She is Chief Medical Officer at St Andrew's Healthcare and is the Associate Registrar for Leadership and Management at the Royal College of Psychiatrists. Correspondence Dr Jennifer Perry, c/o BJPsych Advances, The Royal College of Psychiatrists, 21 Prescot Street, London E1 8BB, UK. Email: jenperry@doctors.org.uk 
performance improvements (e.g. reducing waiting times), they have also been held responsible for patient harm by reducing focus on the patient and care integration (Gubb 2009; Spicer 2009). There is a need for this to change, and there are some examples of where it already has. Leadership and management training is being incorporated into medical degrees. In the UK, there has been the formation of organisations such as the Faculty of Medical Leadership and Management. There is a need for doctors to accept their role as both leaders and managers. The General Medical Council's (GMC's) Good Medical Practice guidance states: 'you must be competent in all aspects of your work, including management' (GMC 2013). Further GMC guidelines lay out the duties of a doctor in the workplace, which include 'demonstrating effective team working and leadership' (GMC 2012a).

Doctors can take on leadership and management roles at various levels: that of the patient, the team and the organisation.

\section{Patient-level leadership and management}

There will always be some patients who prefer to see a psychiatrist. Reed (1991) describes the role of the consultant as the patient's personal doctor 'at the highest medical level in whom [the patient] can place his trust and confide the most intimate of his aspirations fears and secrets in the assurance of confidentiality [...] The advantages of this personal doctor service, where responsibility is accepted by and anchored in a named individual rather than "a service" or "a team" are clear and are certainly appreciated by our patients'.

Indeed, the government, supported by the Academy of Medical Royal Colleges, has more recently developed the Name over the Bed initiative (Academy of Medical Royal Colleges 2014). The initiative ensures that patients have a named responsible consultant/clinician who takes overall responsibility for all aspects of their care. Patients should know who their responsible consultant/clinician is. This was developed as a result of one of the Francis Report's (Francis 2013), key recommendations that if a named clinician were accountable throughout a patient's treatment in hospital, then patient safety and the overall quality of care could be improved. Psychiatrists are able to take on this role and be accountable for the care of their patients.

Another result of the Francis Report is the greater focus on a doctor's responsibility to raise concerns. When psychiatrists have concerns about patient safety, they have a professional responsibility, as outlined by the GMC (2012b), to raise these concerns. There is also the professional duty of candour (GMC 2015), which sets out how doctors must be open and honest when things go wrong or if a patient has suffered harm or distress. Given that, at times, raising concerns or being open about things going wrong may conflict with professional and personal loyalties, it can take great courage and leadership to do so.

A paper by Craddock et al (2010) describes how, at an individual patient level, psychiatrists are able to provide good care, particularly in complex cases. As a result of their training, they have a unique understanding of the biopsychosocial model of illness and the interplay between physical and mental health. This gives them expert skills in diagnosis and management. Psychiatrists are able to use their management skills in coordinating and overseeing situations where treatment for patients involves multiple modalities (e.g. overseeing medication, psychological therapy and occupational therapy). When patients require input from other medical specialties, psychiatrists, owing to their knowledge of healthcare systems, are well positioned to facilitate and organise this. Psychiatrists can also organise input from agencies such as social services and the voluntary sector, if patients require this. When considering treatment, psychiatrists are able to show leadership and make informed judgements about when to depart from management protocols and guidelines. This is important because the complex nature of mental ill-health means that patients' needs are not always best served by rigid adherence to guidelines (Craddock 2010).

\section{Leading teams}

Working in a team is a central feature of psychiatric practice, and without clear leadership and effective communication teams, do not work well and often fail to achieve what they set out to do.

It is recognised that there are differing opinions on whether or not consultant psychiatrists should lead multidisciplinary teams (MDTs). In discussing the role of consultant psychiatrists, the Royal College of Psychiatrists (2010: p. 13) states that 'a consultant psychiatrist can, and indeed is uniquely positioned to, lead a team in such a way that practice and outcomes for patients are good and are continuously improving'. Psychiatrists are skilled in building rapport, negotiating, understanding group dynamics and managing conflict, all of which are useful for working within teams (Johnson 2013).

A group of professional bodies, among them the Academy of Medical Royal Colleges and the British Medical Association, have issued a consensus statement on the role of the doctor, 
which states: 'Doctors alone amongst healthcare professionals must be capable of regularly taking ultimate responsibility for difficult decisions in situations of clinical complexity and uncertainty, drawing on their scientific knowledge and well developed clinical judgement' (Medical Schools Council 2008). Within teams, there is often shared decision-making and distributed responsibility, but there will be times when one person in the team needs to take a difficult decision, and this is likely to be related to situations of complexity or uncertainty.

\section{Leading organisations}

Mental health services continue to undergo significant changes as they move from institutionbased services to locally based ones, and change demands leadership.

Bohmer (2012) describes why doctors should be involved in medical leadership. At the highest level, it is the clinicians who will keep the politicians who reform healthcare delivery systems focused on patient well-being. Arguably, it is only those clinicians working within healthcare systems who are able to understand their complex nature. Therefore, they are best placed to understand what is doable and affordable, thus optimising organisational performance and improving outcomes.

Goodall (2011) looked at data from the top 100 US hospitals in 2009, as identified by the index of hospital quality (a widely used media-generated ranking of quality). She looked at three specialties: cancer, digestive disorders and heart disease/heart surgery. Her study showed that there was a strong positive association between the ranked quality of a hospital and whether the chief executive officer (CEO) was a physician $(P<0.001)$.

There are only a few CEOs working in UK healthcare organisations who are psychiatrists. Matthew Patrick, CEO of South London and Maudsley NHS Trust gave his views on why leadership in psychiatry is important:

'As a psychiatrist who for eight years has worked as the chief executive of two NHS Foundation Trusts, I have come to believe that the skills acquired as a part of psychiatric training are of enormous value in leadership roles. Psychiatrists are trained to reflect, to understand themselves and other people's lives, thoughts, wishes and fears. Leadership requires the same understanding - as organisations are not structures, but living networks of relationships and people.

Psychiatrists share (or should share) a passion to alleviate human suffering, and it is easier to light a fire inside people if you first embody this energy and commitment yourself. Key qualities required by psychiatrists also make for good leadership. Authenticity - an ability to be human and to be yourself, including at times an acknowledgement of your own vulnerability; courage - to act when you know what's right but admit when you've got it wrong; mindfulness - an understanding of your own emotional valency is key; and lastly, an ability to listen - to yourself and the different narratives and perspectives around you.

Leadership is also a team sport. Psychiatrists are trained to work within complex teams containing different professionals and views. We learn that to work well teams need honesty and compassion, even when making hard decisions.

And finally, not restricted to psychiatrists, but don't forget your sense of humour; you will need it' (M. Patrick, personal communication, 2016).

Doctors in leadership roles are expected to help ease opposition among their peers. A leader's status depends on their perceived competence, and one can argue that those who have worked as doctors are more credible. Falcone $\&$ Satiani (2008) describe how doctors in leadership positions act as role models for medical staff, and their presence may help hospitals to attract other talented medical personnel. Medical leaders are likely to share the same values as clinical staff and, therefore, they may create better working conditions for them. Thus, one can argue that you need doctors to lead doctors. Box 3 summarises the reasons why doctors are good medical leaders within organisations.

Medical engagement is associated with better outcomes in healthcare. Engagement is 'a persistent, positive affective motivational state of fulfilment in employees that is characterised by vigour, dedication and absorption' (Shaufeli 2004). Engagement is a two-way process: organisations work to engage employees, with employees having a degree of choice in their response (MacLeod 2009). West \& Dawson (2012) highlight a study by Prins et al (Prins 2010) of more than 2000 Dutch doctors, which found that those who were more engaged were significantly less likely to make mistakes. They also report on a study by Laschinger \& Leiter (2006) of more than 8000 hospital nurses, which found that higher engagement was linked to safer patient care.

BOX 3 Reasons why doctors are good medical leaders within organisations

- Doctors understand the complex healthcare systems

- They have credibility among other staff

- They act as role models

- They share the same values as other clinical staff

- Medical leadership at an organisational level is associated with better patient outcomes, e.g. improved patient safety and lower mortality rates 


\section{Leadership and management styles}

There are numerous models and theories of leadership style, dating back many years. Lewin et al (1939) identified authoritarian, democratic and laissez-faire styles of leadership and demonstrated that leadership style has a significant effect on group productivity and group interactions. Goleman (2000) described a set of six leadership styles, namely: affiliative, coaching, coercive/ commanding, democratic, pace-setting and authoritative. These styles are based on aspects of emotional intelligence (Box 4).

A key element of both leadership and management is communication. About 40 years ago, a study of managers and their roles in the British Overseas Airways Corporation reported that communication skills were critical (Rackham 1977). Three groups were identified: 'not performing', 'successful' and 'super-successful'. The study examined the differences between 'successful' and 'super-successful' and found that these groups demonstrated different types of communication. Managers used two different styles, 'push' and 'pull'. The 'super-successful' managers were able to switch between those styles depending on the situation, whereas 'successful' managers tended to use only one style. More recently, such adaptability has been described as situational leadership, whereby leaders are able to assess a situation and change their style depending on the readiness, current skills and developmental level of team members (Hersey 2008).

Chapman et al (2014) demonstrated that the medical leaders in their study had a variety of patterns of use of leadership styles. The most frequently used styles were found to be affiliative, democratic and authoritative. Use of leadership styles was influenced by a range

BOX 4 Leadership styles

- Commanding/coercive: expects and demands immediate compliance of employees

- Authoritative: provides long-term vision and leadership for the team

- Affiliative: promotes good relationships, communication and trust within the team

- Democratic: encourages group participation to build consensus

- Pace-setting: leads by example, sets high standards for themselves and others, focuses on getting results

- Coaching: supports the personal and professional development of other employees on the team

(Goleman 2000) of factors, including: external factors affecting the organisation; personal style preferences and wisdom; the activity being undertaken; and team, individual or organisational experience or expectation of leadership style in that setting.

The King's Fund (2012) describes how the dominant NHS leadership style has historically been pace-setting. This is characterised by leading from the front, laying down targets and having minimal collaboration with peers. Evidence from various sources, including the Francis Report (Francis 2013) suggests that this top-down approach actually results in poor-quality care. The report acknowledges that a new approach is required for NHS leaders. One approach that might be suitable is the "engaging leadership model' (Alimo-Metcalfe 2008), which emphasises teamwork, collaboration and connectedness. With this model, ideas are listened to, mistakes are used as learning opportunities and managers are engaged with staff members.

\section{What makes psychiatrists great leaders?}

Psychiatrists, as a result of their training, have developed many of the necessary skills to be good medical leaders. Psychiatric training encompasses many of the key components of selfawareness and self-regulation. Psychiatrists spend years thinking about their own feelings to better understand interpersonal interactions. Some undergo their own personal psychotherapy. They develop strategies to become aware of their own feelings and are able to quell impulsive reactions to patients so that they remain calm in the face of difficulties (Johnson 2013). Stanton et al (2011) assessed emotional intelligence in psychiatrists and surgeons. The study found that psychiatrists scored higher than surgeons in emotional selfawareness and empathy. The authors commented: 'One would expect psychiatrists to be more empathic and emotionally reflective, thinkers and feelers'.

Psychiatrists, by the very nature of their work, are seeking to develop people, and one marker of outstanding leadership is the development of other leaders. Ferguson (2011: p. 103) argues that when you have influence over another individual, you are in fact leading them. She goes on to state that outstanding managers, on the other hand, drive individuals to perform at the highest level they are capable of, and that this is more about control, as opposed to the freedom that leadership affords.

\section{Conclusions}

The literature shows that psychiatrists are potentially well suited to undertaking leadership 
and management roles at a patient, team and organisational level. Having medical leadership at these levels is associated with better patient outcomes.

Many doctors are, however, reluctant to take on leadership roles and, if they do so, are often not sufficiently empowered to achieve transformation. Although it is not easy to tackle barriers, it is essential that doctors embrace both leadership and management enthusiastically and take on responsibility for the quality and cost of care. Doctors need to be equally comfortable talking about quality and outcomes, productivity and efficiency, if they are to achieve necessary change in health services.

So, if we are to transform mental healthcare in current times, we must redouble our efforts to involve doctors in leading work to improve performance and do so as a matter of urgency. Not all doctors will have the necessary skills, so leadership and management experience with supervision and training is essential. Ensuring that medical talent is harnessed is key: our healthcare systems generally promote those of seniority rather than those with appropriate skill sets, and we need to embed a culture of meritocracy and engagement across all grades of staff.

\section{Acknowledgements}

We would like to thank the Value of Psychiatry working group at the Royal College of Psychiatrists, which gave us the idea for this article. We also thank Dr Matthew Patrick, CEO at South London and Maudsley NHS Foundation Trust, for his quote on leadership.

\section{References}

Academy of Medical Royal Colleges (2014) Guidance for Taking Responsibility: Accountable Clinicians and Informed Patients. AMRC.

Alimo-Metcalfe B, Alban-Metcalfe J (2008) Engaging Leadership: Creating Organisations that Maximise the Potential of their People. Chartered Institute of Personnel and Development.

Berwick D (2015) Exploring the NHS five year forward view new models of care (video presentation). The Kings Fund (http://www. kingsfund.org.uk/events/nhs-five-year-forward-view-new-modelscare). Accessed 6 June 2016

Bohmer R (2012) The Instrumental Value of Medical Leadership: Engaging Doctors in Improving Services. King's Fund.

Chapman ALN, Johnson D, Kilner K (2014) Leadership styles used by senior medical leaders: patterns, influences and implications for leadership development. Leadership in Health Services, 27: 283-98.

Craddock N, Kerr M, Thapar A (2010) What is the core expertise of the psychiatrist? The Psychiatrist, 34: 457-60.

Department of Health (2010) Responsibility and Accountability: Moving on for New Ways of Working to a Creative, Capable Workforce. Department of Health.

Falcone BE, Satiani B (2008) Physician as hospital chief executive officer. Vascular and Endovascular Surgery, 42: 88-94.
Ferguson P (2011) The Living Leader: Become the Leader you Want to $B e$. The Infinite Ideas Company.

Francis R (2013) Report of the Mid Staffordshire NHS Foundation Trust Public Inquiry: Executive Summary. TSO (The Stationery Office).

General Medical Council (2012a) Leadership and Management for All Doctors. GMC

General Medical Council (2012b) Raising and Acting on Concerns about Patient Safety. GMC.

General Medical Council (2013) Develop and maintain your professional performance. In Good Medical Practice: paras 7-13. GMC.

General Medical Council, Nursing and Midwifery Council (2015) Openness and Honesty when Things go Wrong: The Professional Duty of Candour. GMC/NMC.

Goleman D (2000) Leadership that gets results. Harvard Business Review, March-April: 78-90.

Goodall A (2011) Physician-leaders and hospital performance: is there an association? Social Science \& Medicine, 73: 535-9.

Gubb J (2009) Have targets done more harm than good in the English NHS? BMJ, 338: a3130.

Ham C (2013) Strong medical leaders: the key to high-quality care in these austere times? King's Fund blog, 17 September (http://www. kingsfund.org.uk/blog/2013/09/strong-medical-leaders-key-highquality-care-these-austere-times). Accessed 19 May 2016.

Hersey P, Blanchard KH, Johnson DE (2008) Management of Organizational Behavior: Leading Human Resources (9th edn). Prentice Hall.

Johnson JM, Stern TA (2013) Preparing psychiatrists for leadership roles in healthcare. Academic Psychiatry, 37: 297-300

King's Fund (2012) Leadership and Engagement for Improvement in the NHS: Together we Can. The King's Fund.

Laschinger HKS, Leiter MP (2006) The impact of nursing work environments on patient safety outcomes: the mediating role of burnout/engagement. Journal of Nursing Administration, 5: 259-67.

Lewin K, Lippitt R, White RK (1939) Patterns of aggressive behavior in experimentally created 'social climates'. Journal of Social Psychology, 10: 271-99.

MacLeod D, Clarke N (2009) Engaging for Success: Enhancing Performance through Employee Engagement. TSO (The Stationery Office).

Medical Schools Council (2008) The Consensus Statement of the Role of the Doctor. MSC

Prins JT, Hoekstra-Weebers JE, Gazendam-Donofrio SM, et al (2010) Burnout and engagement among resident doctors in the Netherlands: a national study. Medical Education, 44: 236-47.

Rackham N (1977) Developing negotiating skills. Industrial and Commercial Training, 4: 266-75.

Reed J (1991) The future for psychiatry. Psychiatric Bulletin, 15: 396401.

Royal College of Psychiatrists (2010) Role of the Consultant Psychiatrist: Leadership and Excellence in Mental Health Services (Occasional Paper OP74). Royal College of Psychiatrists.

Schaufeli WB, Bakker ABR (2004) Job demands, job resources, and their relationship with burnout and engagement: a multi-sample study. Journal of Organizational Behavior, 25: 293-315.

Spicer R (2009) Targets harm patients and are destroying the English NHS. International Journal of Clinical Practice, 63: 1278-81.

Stanton C, Sethi FN, Dale 0, et al (2011) Comparison of emotional intelligence between psychiatrists and surgeons. Psychiatric Bulletin, 35: $124-9$

West M, Dawson J (2012) Employee Engagement and NHS Performance. The King's Fund.
MCQ answers

1 c $\quad 2$ d 3 c 4 a 5 e 


\section{MCQs}

Select the single best option for each question stem

1 As regards the difference between leadership and management:

a leadership is about planning, organising, budgeting, troubleshooting and delivering results through the efforts of others; management concerns vision and strategy

b leadership concerns vision and strategy; management focuses on people, the future and on areas where there is often limited certainty and no agreement

c leadership concerns vision and strategy; management is about planning, organising, budgeting, troubleshooting and delivering results through the efforts of others

d outstanding leaders develop leaders of the future; management focuses on people, the future and on areas where there is often limited certainty and no agreement

e leadership focuses on efficiency and the present; management operates best where there is certainty and agreement.

2 Pick the false statement. Engaging doctors in medical leadership and management is essential to:

a drive prevention, early diagnosis and intervention b integrate responses to physical and mental healthcare

c engage patients and support self-management

$d$ reduce the number of non-medical managers in the NHS

e monitor outcomes.

3 The following initiatives have been introduced in the UK to encourage doctors to develop leadership and management skills. Which of these statements is false?

a The Faculty of Medical Leadership and Management has been developed to support doctors in developing their leadership and management skills

b The Faculty of Medical Leadership and Management has developed standards in leadership and management for medical professionals

c Leadership and management is being introduced into most curricula for doctors in training, however it is not suitable for undergraduate medical school curricula

d Schemes have been set up in some organisations where doctors can shadow senior managers and leaders

e There is a GMC Leadership and Management document which sets out a doctor's duties.
4 The Name over the Bed initiative:

a ensures that patients have a named responsible consultant/clinician who takes overall responsibility for all aspects of their care

b was developed by the Care Quality Commission

c ensures that patients own details are written above their hospital bed to improve patient safety

d was developed as a result of the Dalton Review

e was developed as a result of the Five Year Forward View.

5 What qualities do doctors possess that can make them good medical leaders?

a Doctors know the complex healthcare system

b They act as role models

c They share the same values as clinical staff

d Medical leadership at an organisational level is associated with better patient outcomes

e All of the above. 